\title{
El derecho romano y la formación del jurista*
}

\section{FERNANDO HINESTROSA*}

I. Aún estamos en el siglo xx; valga esta precisión liminar que hace alguien que, enclavado en él, ha de intuir, imaginar ilusionado el porvenir, como buen positivista, provisto de la propia experiencia y de muchas otras precedentes, de las que no le es dable renegar en razón de un cambio de centuria y de milenio.

En lo que concierne a la materia de este encuentro y al tema de la exposición, es ineludible preguntarse por el perfil y la armazón del profesional del derecho del presente y del futuro, hasta donde alcance nuestra visión, vaya a saberse qué tan influida por nuestro deseo. ¿Cómo vemos al abogado de hoy y cómo imaginamos al de la próxima generación? Y, con mayor propiedad, ¿cómo se ve a sí mismo él y cómo cree que va a ser su desempeño futuro, y, por lo mismo, cómo quisieran los profesores preparar a ese trabajador, cada vez más profesional y menos intelectual? Cuántas veces no se advierte que la sociedad que sea -hoy se habla de la comunidad internacional- no solamente ha de prever el futuro, sino que tiene el poder, si que también el deber, de construirlo o, cuando me-

Ponencia presentada en el xir Congreso Latinoamericano de Derecho Romano, Ciudad de Panamá, República de Panamá, I6 a I 8 de agosto de 2000.

Para citar el artículo: F. Hinestrosa, "El derecho romano y la formación del jurista", Revista de Derecho Privado, Universidad Externado de Colombia, n. ${ }^{\circ} 29$, julio-diciembre de 2015 , pp. 5-I 2. DOI: http://dx.doi.org/ro.1860 I/or 234366.n29.01

** Rector de la Universidad Externado de Colombia (I 963-20 I 2), Colombia. La Revista de Derecho Privado presenta, a partir del número 24 , los trabajos referidos al derecho civil y romano de quien fuera su fundador y constante y decidido animador. La mayoría de los trabajos ya han sido publicados, pero el afán de facilitar su divulgación, en especial, entre los estudiantes, nos lleva a presentarlos de nuevo, seguros no solo de su utilidad, sino también de su permanente actualidad. 
nos, contribuir a su elaboración. Así, el tema de "la enseñanza del derecho, bic et nunc, adquiere contornos de interés y de proyección que trascienden el del mero diseño de un plan de estudios y la formulación de un programa de clase. Es un lugar común el aserto de que cada quien, mejor, cada generación, tiende a educar a la siguiente, conforme al molde de su propia formación. La enseñanza, por lo mismo que tiene por misión transmitir un saber, tiende a conservar lo que viene en curso, pese al encarecimiento repetido de la función investigadora $y$, por ende, creadora de la Universidad.

¿Cuál el estado actual del derecho? ¿Se podrá hablar de un nuevo derecho? Hay un nuevo derecho que no solo yace en las cláusulas de las constituciones y de las leyes y decretos recientes, sino que, más ampliamente, se encuentra en la doctrina que han ido sentando las sucesivas Cortes constitucionales, y en la conciencia de apertura y de renovación que se ha ido formando entre los profesionales jurídicos y en la gente en general. En todos los campos hay nuevas codificaciones: de organización judicial, penal, laboral, de previsión y seguridad sociales, de familia, de contratación estatal, de comercio, de procedimiento: penal, civil y administrativo, fuera de multitud de estatutos especializados. Y en cuanto a la aplicación, se sueña con un derecho directo, sencillo, de conciliación, de concertación, solidario, genuino, auténtico, basado más en el contenido que en la forma, que prefiera la razón y la equidad a la liturgia. En fin, no se trata simplemente del advenimiento de unos ordenamientos que subrogan a los precedentes, sino de una nueva mentalidad vertida en ellos, que exige su interpretación y aplicación con el criterio propio de ellos, y no con la mente puesta en la normatividad derogada.

¿Qué se puede augurar del derecho de comienzos del tercer milenio? ¿Cuáles serán el lugar y las perspectivas del profesional del derecho del próximo siglo y, por lo mismo, cuál habrá de ser su dotación y cuál su actitud? Preguntas que envuelven otras complementarias: ¿qué clase de ocupaciones, independientes o subordinadas y con qué caracteres se le ofrecerán? ¿Qué conocimientos, destrezas, aptitudes y actitudes se esperan o se demandarán del nuevo jurista? ¿Cómo ha de responder la universidad a su formación? ¿Cómo mantener y fortalecer los caracteres que corresponden a virtudes cívicas y calidades académicas e impulsar a los profesionales en formación en esa dirección y proveerlos de criterio, conocimientos, disciplina personal, aspiraciones, del sentido de responsabilidad, el temple de carácter y la deontología correspondientes a esa nueva proyección?

Fundamentales al efecto son tanto los planes de estudio como la metodología. En lo que respecta a aquellos, recurrentemente se encarece que el joven tenga oportunidad de mirar al universo y a la especie globalmente, que no se imagine que la vida comienza con su generación, sobre todo en una oportunidad en la que los descubrimientos científicos y los adelantos tecnológicos fascinan, deslumbran y engañan, haciendo creer que lo pasado dejó de ser y que es de suyo desechable, y que lo importante y suficiente es ser diestro en el manejo de instrumentos y lenguajes. 
2. De tiempo inmemorial en el diseño de los cursos universitarios fue ineludible la presencia del derecho romano. Hasta que en nuestro siglo, que políticamente no fue, por cierto, de las luces, así concluya en una gran alborada de respeto efectivo de los derechos humanos, un totalitarismo resolvió execrarlo y excluirlo como expresión de materialismo, individualismo y, por si ello fuera poco, semita, de resultas de lo cual hubo de ocultarse bajo el manto amplio de la historia del derecho, en la que los epígonos de otro totalitarismo pretendieron que ocupara un simple capítulo, sepultado en el tiempo. En fin, por esa misma vertiente, de este lado del océano se manifestaron exigencias reivindicativas de las culturas aborígenes y de las integrantes de los nuevos mapas étnicos de América, coligadas, por así decirlo, en su abominación del derecho romano, cuerpo extraño, emisario del derecho privado y, por ende, aliado del capitalismo, proyectadas en la programación académica en su supresión como asignatura autónoma, para alivio de estudiantes lerdos y descargo de las autoridades universitarias de su deber de formación de una especie profesoral con tan reducidas vocaciones como exiguas las oportunidades de desempeño lucrativo de sus cultores, empresa aquella para la que contaron con el apoyo de pragmatistas, nacionalistas y adalides de la denominada posmodernidad, con celo que hace recordar el de los monarcas franceses o normandos o de los comunes castellanos en su respectivo momento.

A decir verdad, y como es del todo explicable, el derecho romano se solió enseñar como una introducción al derecho civil, por tanto tiempo sinónimo del derecho, más con una visión y posición dogmática que histórica e institucional. Personalmente recuerdo el programa que, prescindiendo de la evolución de la res publica romana, iba directo al examen de la familia, los derechos reales, la sucesión y las obligaciones, todo en su versión sincrética justinianea, que le permitía al profesor afirmar anacrónicamente: "los romanos dijeron esto o aquello", sin tener que localizar su aserto en el tiempo, como tampoco en el espacio. Postura muy propicia a hacer ver las leyes nacionales como un trasunto de la Instituta, y el desempeño del jurista como un esfuerzo de aproximación a ese dechado, a la vez que dictado universal, que, a semejanza de las sagradas escrituras, conservaba intacto su valor y su autoridad a lo largo del tiempo, en textos reservados a los iniciados, accesible solo directamente, por conducto de intermediarios calificados. Dijérase que incompatible con el talante rebelde, iconoclasta, de la juventud hodierna.

Nuestros predecesores estudiaron en las Recitaciones del derecho civil según el orden de la Instituta, de Gottlieb Heineccio, o en la Instituta de Álvarez; mi generación hubo de contentarse con Lecciones Elementales, de los profesores nativos, remitidas a las Nociones, de Georges Bry. Pocos tuvieron acceso a las obras de Girard, Petit, Serafini, Arias, y pare de contar. La devoción por el derecho romano en su estado actual se remite a veinticinco años atrás y se entrelaza con el esfuerzo de los académicos italianos congregados por la AssLa y dirigidos por Pierangelo Catalano y Sandro Schipani, presente en sus visitas regulares a América Latina, en los congresos latinoamericanos de derecho romano, como 
también en los encuentros en Italia encaminados a identificar y cultivar las raíces comunes, y sentar los principios de una codificación latinoamericana, y en la formación de profesores nuestros allá. Por lo demás, de entonces y con la misma autoría data el interés de la parte europea por la "romanidad" del derecho latino-americano, hasta entonces tenido simplemente como un apéndice insignificante del derecho continental. Esa aproximación generosa y oportuna ha contribuido, cuando menos, a atemperar el ocaso del derecho romano entre nosotros, más por ausencia de cultores, que en muchas universidades ha sido razón potísima para suprimir el curso, como otrora ocurrió con el de derecho español e indiano.

De aquellos pasados me parece instructivo transcribir estos apartes del Discurso preliminar sobre la necesidad del estudio del derecho romano, que antecede a la tercera edición de la traducción española de la citada obra de Heineccio, publicada en París en i 888, firmada discretamente por D. G. M. P.:

Hasta mediados del siglo pasado era opinión generalmente recibida, la necesidad de estudiar el derecho romano, para ser buen legista y consumado jurisconsulto, que debía formar la principal ocupación del abogado; y al decidirse casi todo por las leyes romanas y por las sentencias de los jurisconsultos de aquella célebre nación, no se tenían, compraban, ni registraban más libros que los comentadores de ellas. Los Bártulos y Baldos eran consultados a cada paso, y con mucha más frecuencia que los escritores de la jurisprudencia nacional. Era tanto el respeto que merecía su doctrina, que llegó a reputarse como una herejía el separarse de sus decisiones. [...] Ideas tan arraigadas durarían aún en nuestros días, si las opiniones de los hombres no mudasen a influjo del tiempo y de otras mil circunstancias que las cambian a cada paso. El hombre, cuando no escucha la voz de la filosofía, y sin colocar las cosas bajo el verdadero punto de vista en que debe verlas, se arroja a formar ideas, crear opiniones, erigir axiomas, sin más mérito ni otro análisis que las primeras impresiones, impulsado de que otros lo sienten así. [...] Esto ha sucedido a los partidarios y a los enemigos absolutos del estudio del derecho romano. Los que lo preconizaban como necesario, indispensable, y como la única fuente y segura guía para las decisiones legales, lo proscribieron luego por inútil, inconducente y aun perjudicial a causa de los errores en que, según su sentir, se nutría a la juventud estudiosa al seguir sus máximas. [...] Fijando esta cuestión y reduciéndola a su verdadero centro, para decidirla con la imparcialidad y tino que exige, bien se la puede concebir y resolver en estos términos: en el estado de nuestra legislación y en el de todos los países de Europa, y aun del Nuevo Mundo, es necesario el estudio de la jurisprudencia romana, para comprender muchas leyes con perfección, saber su origen, los motivos por que se dictaron, y los casos en que tendrán mejor aplicación. [...] Estas mismas razones tienen los príncipes cuando mandan y prescriben en los reglamentos generales de educación pública que se principie por estudiar 
el derecho romano, como que es la guía para conducir a los jóvenes, a que con más claridad lleguen a comprender el sentido y espíritu de las leyes de su país.

3. ¿Qué nos corresponde decir hoy y aquí? ¿Qué es América Latina culturalmente? ¿Será la "frontera occidental” de Europa? ¿Se podrá hablar, en lo que a los pueblos que la componen, de una "recepción" del derecho romano, similar a la que experimentaron sucesivamente, con mayor o menor intensidad, los distintos países europeos, y que al decir de algunos germanistas sectarios los despojó de identidad jurídica? ¿Hasta dónde la raíz romanista de la formación del jurista latinoamericano y de las codificaciones todas del subcontinente es un rasgo fundamental - genuino- de su identidad cultural, y por lo mismo, de una nacionalidad supranacional? ¿Cuál el valor de dicho ius commune latinoamericano como espina dorsal de la integración económica y política, y cuál su solidez como factor de resistencia frente a la penetración avasalladora del common law?

Bien poca es la noticia que tenemos acerca de las instituciones jurídicas en las Indias para la época de la Conquista. Aparte de la diversidad de pueblos y de niveles de civilización, obra negativamente el hecho de la dominación absoluta de parte del colonizador ibérico y su absorción cultural plena de la población aborigen. Los peninsulares y luego también los criollos se formaron en las pautas y leyes de la metrópoli, y los indígenas, como más tarde los africanos, vivieron al margen del derecho hasta avanzada la época republicana: simplemente no eran sujetos de derecho. Los llamados "derecho español e indiano" y "derecho indiano propiamente dicho" fueron del todo románicos. Y cuando, consumada la Independencia, las repúblicas sustituyeron a los virreinatos, capitanías generales y provincias, hubieron de mantener las leyes en curso, ocupadas como estaban en organizarse, no pudiendo dedicarse a la redacción o, siquiera, a la adopción de códigos, naturalmente de cepa distinta de los coloniales -que allí se marca una diferencia entre América Latina y América del Norte. El Code civil français, más tarde el в вв у por último el codice civile de 1942 serían los sucesivos puntos de referencia, cuando no los modelos seguidos, en oportunidades con fidelidad mayor a la aconsejada por el resultado de una ineludible comparación de las circunstancias físicas, económicas y sociales (geopolíticas) de los países europeos y los latinoamericanos.

Nuestra matriz jurídica es romanista, nuestro derecho ha sido por más de cinco siglos, sin solución de continuidad, un derecho continental europeo, es decir, romano-germánico. Nos formamos en él, y lo seguimos viviendo, con independencia de qué tan genuinamente. El hecho es que no solo los códigos básicos, comenzando por la Constitución Política, han tenido ese origen, sino que seguimos abrevando en las mismas fuentes, así en oportunidades se varíe la nomenclatura, incluso para soslayar la inspiración. Somos tributarios de ese tronco común, como por lo demás lo son otros pueblos pertenecientes a civilizaciones menos europeizadas u occidentales, y aun extrañas a él. ¿En cuántas oportunidades, a lo largo del tiempo, con alternativas en la predilección por el 
país de referencia: Francia, Alemania, Italia (no menciono acá a España, por haber sido ella similarmente tributaria)? La doctrina de esos países, si que también la jurisprudencia, en otro tiempo fueron las solas presentes, y aún hoy circulan con ventaja sobre las nacionales, que, por lo demás, se nutren prevalecientemente, cuando no de manera exclusiva, de aquellas. Lo cual tampoco es fenómeno exclusivo de América Latina: en la propia Italia hasta hace poco más de una generación la doctrina civilista citaba con similar intensidad la bibliografía alemana, cuando no con mayor que la nacional. Es que llegar a la autonomía y a la creatividad presupone madurez e implica una robustez política, económica y cultural que va más allá de los deseos y, por supuesto, de la presuntuosidad. De otra parte, aquella similitud, cuando no igualdad, de ordenamientos, y más ciertamente, esa comunidad de origen, desarrollo, colaboración y apoyos, es lo que permite augurar la unidad y, por ende, la viabilidad de América Latina.

4. Luego de las anteriores divagaciones, sigue pendiente la pregunta acerca del papel del derecho romano en la formación del jurista. A cuya respuesta ha de anticiparse el planteamiento de que la presencia del derecho romano ya no podrá defenderse simplemente fincada en el peso de la tradición-inercia, o en el sentimentalismo, o solamente en la necesidad de una postura política de resistencia. O sea que es menester un replanteamiento a fondo de modelos, métodos y sistemas de enseñanza y difusión, para proyectarlo sobre la formación misma del criterio, del carácter, de la Weltanschauung del jurista, en los distintos dominios de su ciencia-arte, si es que se aspira a que trascienda su tarea de manipulador de reglas, y que América Latina no resulte inopinadamente objeto de una "recepción" del common law, sin siquiera posibilidades de rebelión por parte de los prácticos, habida cuenta de la mayor sencillez y pragmatismo de aquel, como ocurre con la lengua inglesa: ¿Begriffsjurisprudenz versus Interessenjurisprudenz?, y, sobre todo, teniendo presente que "quien paga los músicos impone la partitura".

A este propósito, valga anotar, marginalmente, que para nosotros no solo es interesante sino vital seguir el curso de las vicisitudes del derecho en las directivas de la Unión Europea. Así hubiera de presagiarse un "sincretismo jurídico" o tuviéramos que resignarnos a él, el conocimiento del derecho romano, en su devenir histórico, en la espontaneidad de su concepción, entendimiento e interpretación, en sus distintas ramas, a lo largo de la historia, o mejor, en su historicidad, no solo amplía el horizonte conceptual del aspirante al oficio jurídico, sino que ennoblece su visión y engrandece su desempeño, con esos elementos genuinos del criterio latino: la lógica del juicio, el sentido de equidad y la continuidad vital, en una palabra, la interpretatio: de los hechos y de los principios y los sentimientos, primero nacionales y luego universales.

No es esta la primera vez - tampoco será la última- en que la cuestión del derecho romano en la formación del jurista, esto es, del iuris perito, se plantea dilemáticamente en América Latina, plena de prejuicios y apasionamiento, cada vez más simplistamente. En efecto, a los partidos tomados adversos, por razones 
emocionales o ideológicas, en oportunidades -y en los tiempos actuales cada vez más-, se suman posiciones cómodas o, mejor, perezosas. El humanismo, la cultura clásica, la filosofía de la historia, para no hablar de las lenguas clásicas, en fin, el saber reflexivo y la duda metódica, son materias y actividades exigentes, que nunca han sido económicamente retributivas, pero que antaño, a más de prestancia, daban satisfacción personal. Hoy, esta desapareció, sustituida por gustos más toscos, y el afán último es el lucro veloz. Entonces, se advierte, a qué distraer al estudiante de temas y prácticas que lo ponen pronta y eficientemente en condiciones de desempeñarse con profesionalismo. La decodificación del derecho, el surgimiento de nuevas ramas que le ofrecen oportunidad de incrementar aquel rendimiento contribuyen a recargar el plan de estudios y a dejar como núcleo central una suma dispersa de conocimientos y destrezas, que el abogado concretará pronto en una "especialidad". Pragmáticamente lo que procura y exige es manejar, o más propiamente aprender a manipular las leyes. Pretende ser un técnico, al que no han de inquietar los problemas filosóficos, y cuya mente y corazón no tienen por qué agitar los imponderables éticos.

5. Lejos de nuestra posición está el imaginar que solamente la formación jurídica romanista brinda al operador del derecho la sensibilidad, la finura, la delicadeza y la energía indispensables para la formulación de una regla y su aplicación adecuada. Lo que ocurre es que ese derecho, uno y plural, ha mostrado, a lo largo de dos y medio milenios, una prodigiosa capacidad de seducción, de convicción, de adaptación, incomparable, de manera que, con su método, su estilo, su técnica, los pueblos posteriores y sus respectivas organizaciones no solo fueron elaborando variaciones sobre los mismos temas, sino creando figuras nuevas, en respuesta a las exigencias sucesivas de la economía, la política, los modos de producción, distribución y consumo de riqueza y saber; en una palabra, ajustándose a los sucesivos estilos de vida. Por lo mismo, habiendo sido América Latina incorporada a esa corriente (¿transfusión, difusión, recepción?), habiéndose nutrido de ella, y habiendo hecho propia esa tradición, adaptándola a las características de su propio ser, posiblemente con muchas incongruencias frente al modelo, no sería ni providente ni auténtico ignorar una comunidad cultural vernácula de cinco siglos, amalgamada a la experiencia ancestral, y abdicar de la identidad cierta, no digo en búsqueda de modelos ajenos, hasta dónde incompatibles con su ser genuino sino, peor aún, sometiéndose dócilmente a ellos.

Claro está que el "culto" del derecho romano, vertido en la enseñanza tradicional dogmática de las instituciones, y más en su tarea propedéutica del derecho civil, hizo crisis y por doquier se ha venido tratando de liberarlo de esa imagen de anticuario -iquitándole el olor a moho!- y de tomarlo y cultivarlo de modo de preservar los valores pedagógicos -en el más amplio sentido de la expresión- del romanismo, como espina dorsal de la formación jurídica, y, de paso sea dicho, mostrándolo más asequible y haciendo menos pesada su noticia. En tal sentido podría reacuñarse el lema de por el "Derecho romano actual", 
antes que por el derecho de los romanos: o sea rescatar su legado vivo y pleno, al margen tanto de la apología como de la execración; el derecho "romano" como experiencia histórica y, por lo mismo, en toda su "historicidad"; que, por lo demás, es la historia viva de nuestra civilización, como un dato concreto, objetivo, sin entrar en pronunciamientos sobre su superioridad, o sobre su ductilidad, tampoco sobre su vigencia, y mucho menos en la disputa acerca de cuál tiene hoy más vocación de "universalidad", si el ius commune o el common law. Se vislumbra, pues, y se anhela un "derecho romano de hoy", "considerado [a la vez] como instrumento de educación del jurista latinoamericano y como base de un derecho común latinoamericano, que supere [la pluralidad] de las codificaciones por medio de ellas mismas", mediante su acomodación paulatina a las nuevas corrientes y exigencias de los tiempos.

La tan llevada y traída "globalidad" deja en claro la presencia y la utilidad de numerosos puntos comunes, de antaño, recientes, y muchos otros generados a propósito y por fuerza de ella; al propio tiempo que la riqueza y el valor de la diversidad. Sin ir más lejos, la experiencia nos enseña cómo un texto universal ha dicho y puede decir y seguir diciendo muchas cosas distintas a lo largo de los tiempos y a lo ancho de la geografía. No obstante lo cual, o precisamente por ello, es valedera la experiencia romanista de una teoría o parte general, de la formulación de conceptos y principios fundamentales, comunes, que perduran como sedimento mental o de racionalidad, reacio a todo encasillamiento o apropiación ortodoxos. Un derecho romano que ha cabalgado sobre el lomo de los acontecimientos, alternando entre la fluidez y la rigidez, la espontaneidad y el dogmatismo, pero procurando siempre ser racional y justo.

Pensemos, pues, en un derecho romano en el umbral de la carrera de derecho que enseñe al joven lo que ha significado el derecho, cómo se ha generado, su integración con la economía, la política, la moral, sus vicisitudes, las exigencias que pesan sobre él y sus operadores, a partir de la tecné o la Kunst, esa arte, síntesis de ciencia, técnica, ética y estética, que identifica al oficio jurídico. Candorosamente sueño con una aproximación paulatina del alumno primerizo a lo que ha sido dicho oficio, que será el suyo, que comienza con el conocimiento, sigue con el encariñamiento y concluye en la posesión mutua, con ansia de superación, con obsesión de servicio a los ideales universales de paz, de justicia, de solidaridad. 